\title{
Estimation of Fatigue Strength of Reinforced Complete Upper Denture Using a Newly Designed Testing Machine: A Laboratory Research Project
}

\author{
Anthony E. Prombonas ${ }^{1}$ (), Nikolas A. Poulis ${ }^{2}$ (), Evangelos A. Prombonas ${ }^{3}$ \\ ${ }^{1}$ Division of Dental Technology, Department of Biomedical Sciences, School of Health and Care Sciences, University \\ of West Attica, Athens, Greece; ${ }^{2}$ Centre for Dental Sciences, Faculty of Health and Wellbeing, University of Bolton, \\ Manchester, UK; ${ }^{3}$ Master in Information Technology, University of Limoge, Limoges, France
}

Correspondence to: Anthony E. Prombonas, aprob@uniwa.gr

Keywords: Fatigue Testing Machine, Complete Upper Denture, Crack Initiation, Crack Propagation, Fatigue Fracture

Received: December 24, $2020 \quad$ Accepted: February 4, $2021 \quad$ Published: February 7, 2021

Copyright $\odot 2021$ by author(s) and Scientific Research Publishing Inc.

This work is licensed under the Creative Commons Attribution International License (CC BY 4.0).

http://creativecommons.org/licenses/by/4.0/

\section{(c) (i) Open Access}

\section{ABSTRACT}

In the present study, an aero pneumatic fatigue testing machine for complete dentures was designed, fabricated, and tested for the evaluation of the fatigue life of reinforced complete upper denture (CUD). On completion and testing, it was observed that the machine has the potential of generating reliable number of cyclic data. The machine's performance was evaluated using test specimens of identical CUDs that were machined in conformity with standard procedures. The fatigue machine compressed the lower dental arch over the upper denture-specimen in centric occlusion, in the same way that the two masticatory muscles pull the lower jaw over the upper jaw during chewing. The incorporation of glass fibres into the CUD using a sandwich technique quadruples the lifespan of the denture $(P=0.004)$. The low standard deviation, along with the low coefficient of variation $(\mathrm{CV})$ of the group of unreinforced dentures shows the repeatability of the results and the reliability of the machine. The high standard deviation and coefficient of variation of reinforced dentures was expected, since a high variation of results is usually recorded in fibre reinforcement cases. This research confirmed the view that the crack during denture fracture initiates in the anterior palatal area and propagates to the posterior.

\section{INTRODUCTION}

Engineered mechanical structures, such as complete upper dentures (CUD), can be subjected to much more complex systems of loading leading to the multiaxial fatigue damage, where the principal stress va- 
ries in magnitude and direction. Moreover, real (functional) loads can induce bending combined with torsional, axial, and shear stresses, generating bi- or tri-axial variable stress/strain histories at the critical point. Under these conditions, the midline of the palate of the CUD could be the torsion axis of the denture during loading in coexistence with the bending deflection. For these reasons, fatigue strength is the most important mechanical property of the CUD, especially when it is measured under the simulated conditions of its operation during mastication. Only under these conditions can a CUD be subjected to real loading and combined deformation leading to more reliable results [1].

There is a lot of work published internationally on the design and manufacture of fatigue machines for the study of materials in engineering and industry. In some of these machines, pure bending or torsion loads are applied, while in other machines, a combination of these two types of loading (torsion and bending) is applied. In some machines, repeated (cyclic) loading is achieved by the use of a motor (whose rotary motion is converted to pulsed motion), while in others by the use of a hydraulic or air piston that performs pulsed motion (thrust or traction) [2-18].

An investigation of the available bibliography shows that a small number of researchers used their own design and construction machine either to measure the flexural fatigue of acrylic resin used in complete dentures construction or to measure the fatigue strength of the acrylic bases of complete and partial dentures $[19,20]$.

Experimental research has shown that the addition of cross-linking agent or methacrylic acid or both did not improve the fatigue characteristics of the dental PMMA as well as that the fatigue resistance of the denture specimens decreased dramatically $(P=0.002)$ when there was a notch at the anterior margin of the palatal plate in the denture specimen. It has also been shown that the fatigue resistance of acrylic resin removable partial dentures reinforced with glass fibers is superior to those removable partial dentures reinforced with conventional metal wire. Additionally, the fatigue life of the maxillary partial dentures test specimens varied greatly and the correlation between the number of loading cycles and the midline section was poor $(r=0.455)$ [19-23]. Other researchers used experimental apparatuses to study the phenomenon of the CUD fracture. Among other things, the phenomenon of the onset and propagation of the crack was measured, as well as the propagation velocity, which was estimated at $250 \mathrm{~m} / \mathrm{s}$ [23].

The behaviour of a plastic component in service is influenced by several other factors besides the properties of the material used in its manufacture. The fatigue behaviour of plastics is affected by factors like the viscoelasticity (which makes their fatigue behaviour more complex), the type of loading, small changes in temperature, and their low thermal conductivity, leading to hysteretic heating which can build up in plastics causing them to fail in thermal fatigue. Furthermore, the amount of heat generated increases with increasing stress and test frequency. By simplifying and idealizing the test conditions, it would be possible to vary one or a few of the factors that influence the fatigue life and to state their effects. Even if these conditions are fulfilled, there will always remain some unknown and uncontrollable factors that produce a large scatter in fatigue life, even of specimens which are considered to be identical [24].

In the Former Department of Dental Technology (now the Division of Dental Technology of the Department of Biomedical Sciences), of the former TEI of Athens (now the University of West Attica), a dry-fatigue machine (without the presence of saliva) for CUD was designed, manufactured, and operated. This machine was designed to apply repetitive (cyclic) loads to a CUD, in such a way that it resembles the application of masticatory loads to a complete denture under operation conditions in the oral cavity when loads are exerted on it through the muscles of the stomatognathic system.

\subsection{Description of the Machine}

The parts of the fatigue machine that will be described in detail below are as follows:

1) The horizontal base.

2) The vertical base and the load cell for monitoring the attractive force.

3) The grip of transferring loads to the casts. 
4) The side metal guides.

5) The air piston.

6) The air network and the electrical part of the machine

7) The hybrid cast of the upper jaw.

8) The hybrid all-acrylic cast of the mandible.

\subsubsection{The Horizontal Base}

The horizontal base consists of a metal rectangular iron hollow beam from which one large side was removed. This created a $\Pi$-shaped beam measuring $10 \times 5 \times 50 \mathrm{~cm}$. This hollow beam was screwed onto a piece of wood in the shape of a long slab. All other components of the machine were screwed onto the metal base so that during operation, due to its high rigidity, no distortion occurs in any direction (Figure 1).

\subsubsection{The Vertical Base and the Load Cell}

Vertically on the horizontal base, an extremely rigid $(1.2 \mathrm{~cm}$ in thickness) iron L-shaped base was screwed using rigid screws $6.5 \mathrm{~mm}$ in diameter. The vertical base was screwed, so that its axis of symmetry coincided with the axis of symmetry of the horizontal base.

A special load cell (QL-15G load cells, Hanzhong, China load cell) with its connected special recorder was installed with four screws $5 \mathrm{~mm}$ in diameter on a metal base so that it was acting as a cantilever beam (first dynamometer). Given that the recorder has been calibrated to record the force exerted in kgrs, and the loaded pair of casts was supported by the load cell during the experiment, it was possible to record the exerted force through this first dynamometer, directly in kgrs. The load cell was mounted in front of the vertical metal base of the fatigue machine, using rigid screws, with its longitudinal axis perpendicular, and in such a way that the free end of the cantilever was facing downwards.

The load control is also performed with a second dynamometer (load cell), to maintain a constant value of the load during the experiment. This control device was designed by transforming the load grip of the machine to a second dynamometer (load cell) to control the load during the test. For this reason, a uniaxial strain gauge (KFGS-5-60-C1-16, Kyowa Electronic Instruments Co., Ltd., Tokyo, Japan) was cemented on the rear metal beam of the grip. This gauge was the active gauge of a quarter Wheatstone bridge circuit. The strain of the metal beam was measured by connecting the gauge to an electronic six-channel data acquisition system (Wheatstone bridge) consisting of a personal computer, a 12-bit PCI A/D card, a terminal board, and specific acquisition and control software (Advanced GeniDAQ; American Advantech Corporation, Sunnyvale, California, USA). The deformation monitored by this load cell easily corresponds to the force recorded by the first dynamometer. By keeping the deformation of the second load cell constant, the force exerted by the machine on the specimens is kept constant.

\subsubsection{The Grip for Load Transferring}

The load transfer grip is rectangular with short sides of $150 \mathrm{~mm}$ long and long sides of $350 \mathrm{~mm}$ long. The short sides of the grip consist of rigid metal iron beams measuring $150 \times 40 \times 13 \mathrm{~mm}$ for rigidity. These iron beams have holes at their ends, through which two metal screw bars (right and left) pass. The metal beams (front and rear) are placed at the desired distance from each other (adjustable) and are immobilized using double nuts (clamps). The front iron beam has a hole in the middle, through which passes the screw that connects it to the shaft of the piston in order to follow its movements, as shown in Figure 1. The grip was designed in such a way that it applies direct loads to the specimen, such as the lower jaw muscular system applies loads during the bite. These loads are exerted directly on the dentures-specimens without the use of levers. With the proposed design, the load is reproduced with sufficient accuracy, and it is transmitted to the test piece without undue scatter. In machines where the load is transmitted to the specimen through a lever system, weights and forces have to be carefully controlled, including weighing of all levers and other parts of the loading system, together with an experimental determination of the centres of gravity of these parts [18]. 


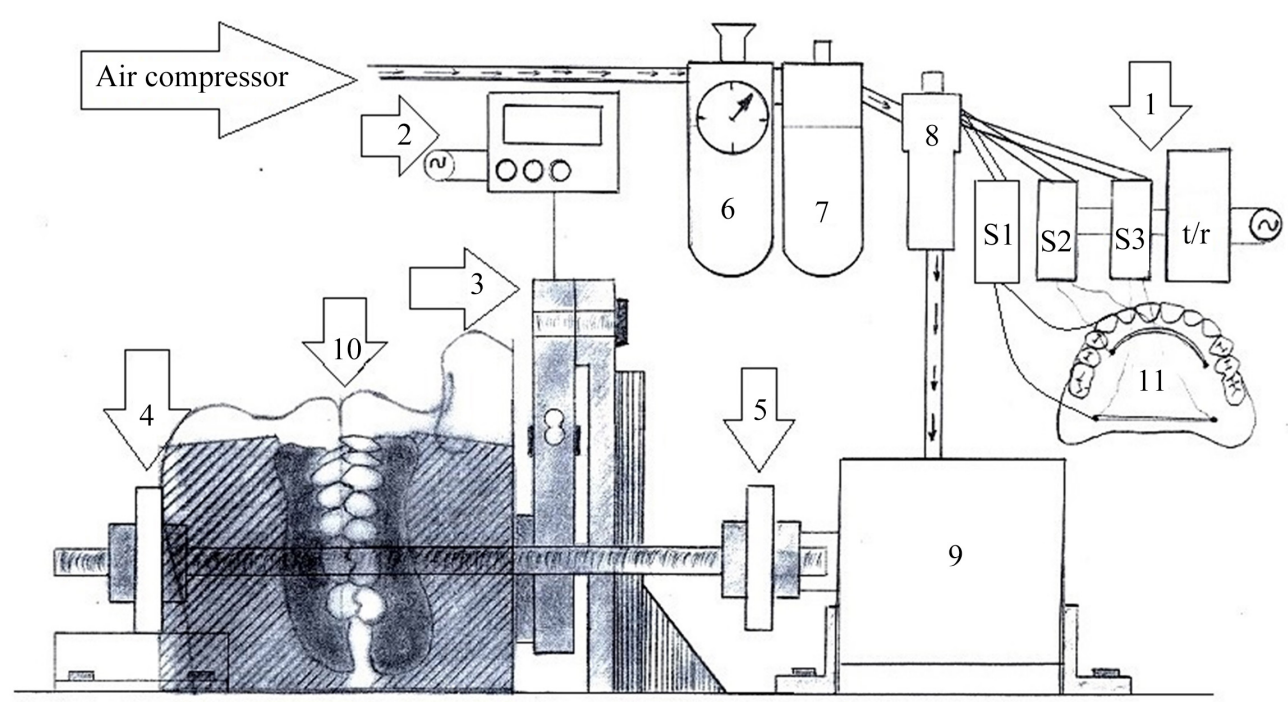

Figure 1 . The fatigue machine in assembly (1, the three electromagnetic switches and the time relay, 2, the digital dynamometer recorder, 3, the 1st load cell (dynamometer) adapted on the vertical base, 4 and 5, the grip, 6 and 7, pressure regulator of electromagnetic valve and lubrication tank, 8 , electromagnetic valve, 9 , air piston, 10, the complete upper denture on the loading cast in centric oclussion with the hybrid acrylic lower jaw cast and, 11, the specimen of the complete upper denture with the sensors connected to the electromagnetic switches.

\subsubsection{The Side Metal Guides}

To the right and left of the horizontal metal base and in a parallel direction to the longitudinal axis of the base, elongated metal guides with a height of $30 \mathrm{~mm}$ are immobilized with screws. The rear iron beam of the grip is placed on these guides, in a way that during the function the grip remains in a horizontal position.

\subsubsection{The Air Piston}

The air piston (Air Copm, Stampotecnica, pneumatic components, Via Martiri di Cervarolo, Correggio, Modena, Italy) with shaft cross-section of $60 \mathrm{~mm}$, develops a stable maximum load of $311 \mathrm{kgrs}$ during thrust and 291 kgrs during traction, at an air pressure of 10 bars. The piston was mounted on the horizontal metal base of the machine in a way that the central axis of the piston coincided with the central axis of the base. There is the possibility of adjusting the exerted force by altering the air pressure, according to the manufacturer calibration diagram of Figure 2 .

\subsubsection{The Air Network and the Electrical Part of the Machine}

As far as it concerns the air network, the air produced by an air compressor (Jun Air Compressor-Model 6, Denmark) is fed into the piston, through a system that includes the filter with the pressure regulator and the lubricator with the lubricating oil tank. Finally, the air under known pressure is transferred to the electromagnetic valve (electro-pneumatic valve or solenoid valve, Line 127, Air Copm, Stampotecnica, Pneumatic Components, Via Martiri di Cervarolo, Correggio, Modena, Italy), from which it is released to the piston periodically, with a frequency regulated by the machine's electrical system (time relay). The piston is set to perform traction (i.e., inwards movement of the shaft).

A time relay (Electronic timer E234 CT-MFD, ABB Ltd, Zurich, Switzerland) is used to produce an electric pulse of known frequency. A cable circuit transmits the electric pulse to the electromagnetic valve, which opens and closes with the frequency of the pulse. 


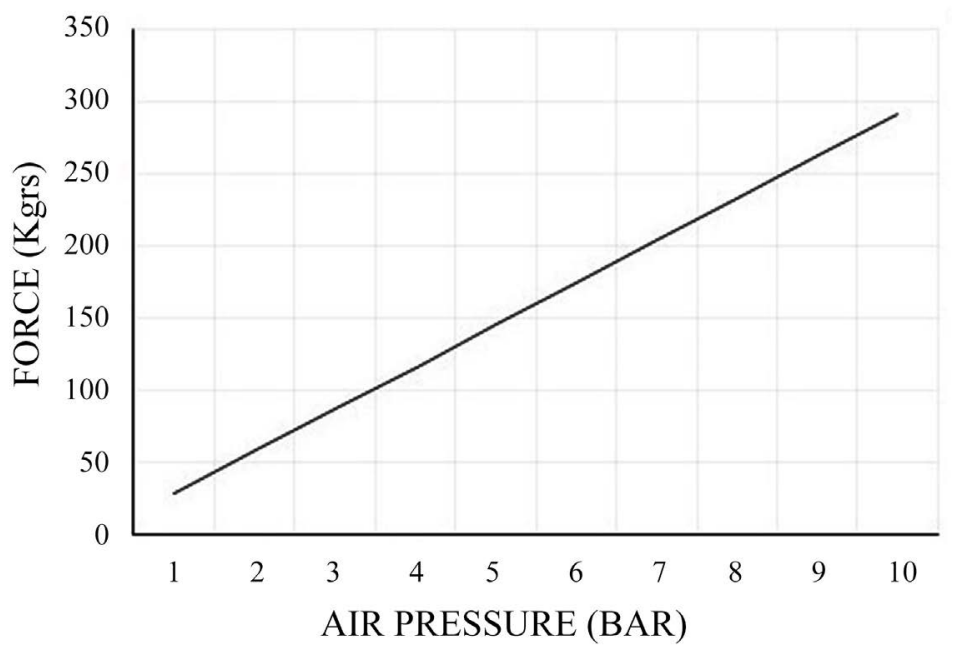

Figure 2. The calibration curve of air piston (Data from Air Comp, Stampotecnica, pneumatic components, Via Martiri di Cervarolo, Correggio, Modena, Italy).

The electrical system of the machine is supplemented by a system of three electromagnetic DC power switches, S1, S2, and S3 (Humfree Contactor 25A, electromagnetic switch Huger ESL 225 SDC, Germany), and two digital electric pulse meters (Conch, Digital Counter, 220V, Taiwan).

The two electromagnetic switches S1 and S2 were connected to the two copper sensors (very thin sheets of $\mathrm{Cu}$ measuring $20 \times 2 \times 0.2 \mathrm{~mm}$ ) cemented on the anterior and posterior area of the palate, while the third switch was connected to the two copper sensors cemented on the most anterior and posterior boundaries of the CUD. The electromagnetic switches, the sensors, and the digital electric pulse meters were installed in such a way as to detect the location of the crack initiation (anterior or posterior area) as well as the direction of its propagation.

The electric pulse, before it reaches the electromagnetic air valve, passes through the circuit of the three electromagnetic power switches, the two digital electric pulse meters (Conch, Digital Counter, 220V, Taiwan) and the copper sensors.

When a crack appears in the sensor area, this crack runs through not only the acrylic base but also through the corresponding sensor. Subsequently the electromagnetic switch, which is connected to the sensor opens, the corresponding pulse meter is interrupted, and its operation stops. In this way, it is ascertained in how many loadings cycles a crack is created in the corresponding sensor area (anterior or posterior palatal area).

It should be noted that the shutdown of the two pulse meters (S1 and S2) does not interrupt the operation of the machine. The operation of the machine (interruption of power supply in case of total-catastrophic fracture) is controlled by the third electromagnetic switch S3. The direct current that arms this electromagnetic switch passes through the two supplementary copper sensors that are cemented on the two most anterior and posterior boundaries of the denture (Figure 3).

\subsubsection{The Hybrid Cast of the Upper Jaw}

Two commercial moulds of edentulous jaws were used: one of the upper and one of the lower jaws (Edentulous moulds, size 55; Columbia Dentoform, Long Island, New York, USA) to fabricate the two prototype wax denture bases as well as the identical waxed complete dentures of this research.

The cast on which each denture-specimen was placed for fatigue loading was constructed by pouring high-strength type IV dental stone (Vel-Mix, KerrLab) into the commercial mould of the upper jaw. Using the elastic mould of the upper jaw, the special cast for loading the complete dentures-specimens was produced by pouring dental stone (Hydrock KerrLab; Orange, Orange, California, USA) in a way that the final thickness of the cast was $40 \mathrm{~mm}$ thick, for maximum strength and rigidity [25-28]. 


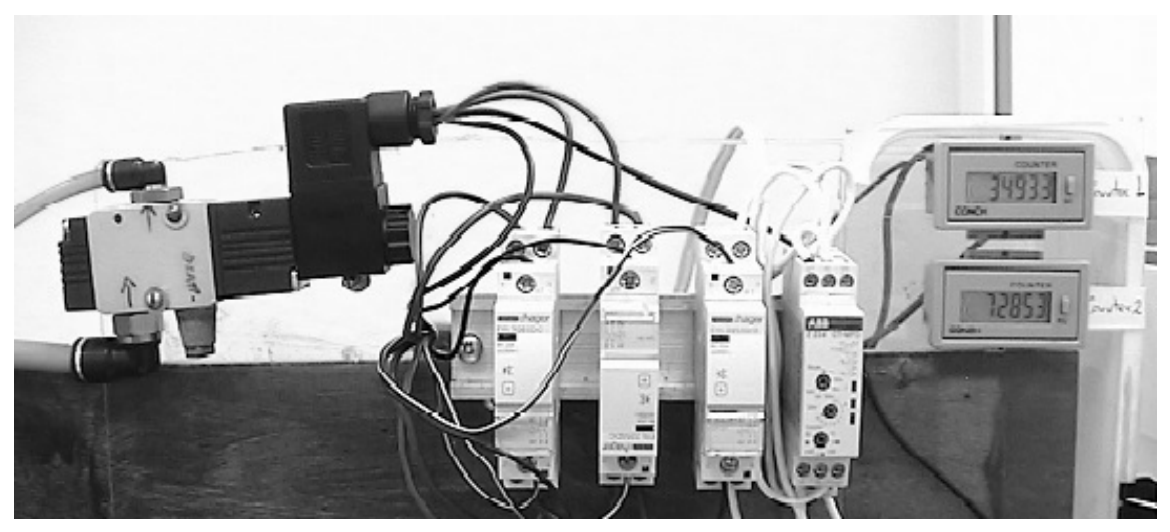

Figure 3. The electric system of the machine. Electromagnetic valve (left), the three electromagnetic switches (S1, S2 and S3), the time relay (middle), and the two electric pulse meters (right).

With the help of a tungsten carbide bur (D253 KG 60, Bredent, Germany), the dental stone was removed along the palatal mesial line, from the area of labial fraenum to the posterior border of the palate, creating a rectangular groove $2.5 \mathrm{~mm}$ in depth and $8 \mathrm{~mm}$ in width. Inside this groove, wax for inlays was poured, producing the wax model of the rectangular groove. From this model, the positive metal representation of the groove was constructed, by casting bronze (C85500 Alloy, Hastings Brass Foundry Ltd, Vancouver, CANADA). After casting, the metal model of the sagittal area of the palate was adjusted to its position in the groove of the cast, smoothed and polished.

Gypsum was then removed around the cast in the area of the labial and buccal vestibule (alveoabial and alveolingual sulcus) for a depth of $2 \mathrm{~mm}$ and replaced by an equal amount of medium silicone (Coltex Medium, Coltene, West Sussex, UK). After the silicone polymerization, gypsum was removed in the depth of $3 \mathrm{~mm}$, to the right and left of the metal model of the sagittal palatal region, as well as from the top of the residual alveolar ridges. The previously made silicone (corresponding to the labial and buccal vestibules) was removed along the entire length of the vestibule (sulcus), except for four sections: two 13-mm long in the area of the right and left canines and two of the same length in the areas of the right and left tuberosities.

The result of the described process was the construction of a hybrid cast that has a metal sagittal region protruding from the rest of the cast with four silicone stoppers on the labial and buccal vestibules. Any identical denture-specimen placed on the cast comes in contact along the sagittal line (midline) with the metal model of the sagittal palatal region and the four silicone stoppers in the area of the labial and buccal vestibules. The rest of the inner surface of the denture does not come into contact with the cast. Each denture-specimen placed on the cast and loaded during the fatigue test bends freely on the fulcrum of the metal sagittal region, with which it comes into constant contact. A similar case has been used by other researchers without the modifications described in this paper (Figure 4) [20-22].

\subsubsection{The Hybrid All-Acrylic Cast of the Mandible}

The cast of the lower jaw, which is placed in centric occlusion with the identical dentures-specimens to perform the fatigue test, which acts as a means of transporting the loads on these specimens, was constructed as follows:

The wax model of the complete lower denture, which was made with a well-known methodology, was imprinted (duplicated) with the help of a putty silicone (Coltoflax, Colten, West Sussex, UK). In the inner part of the impression corresponding to the posterior teeth of the lower jaw (impressions of artificial teeth) casting wax was poured, the wax was removed from the imprints, sprues were placed, and a cast was produced using casting bronze (C85500 Alloy, Hastings Brass Foundry Ltd, Vancouver, CANADA). After casting, the metal reproductions of the posterior teeth were smoothed and polished [25-28]. 


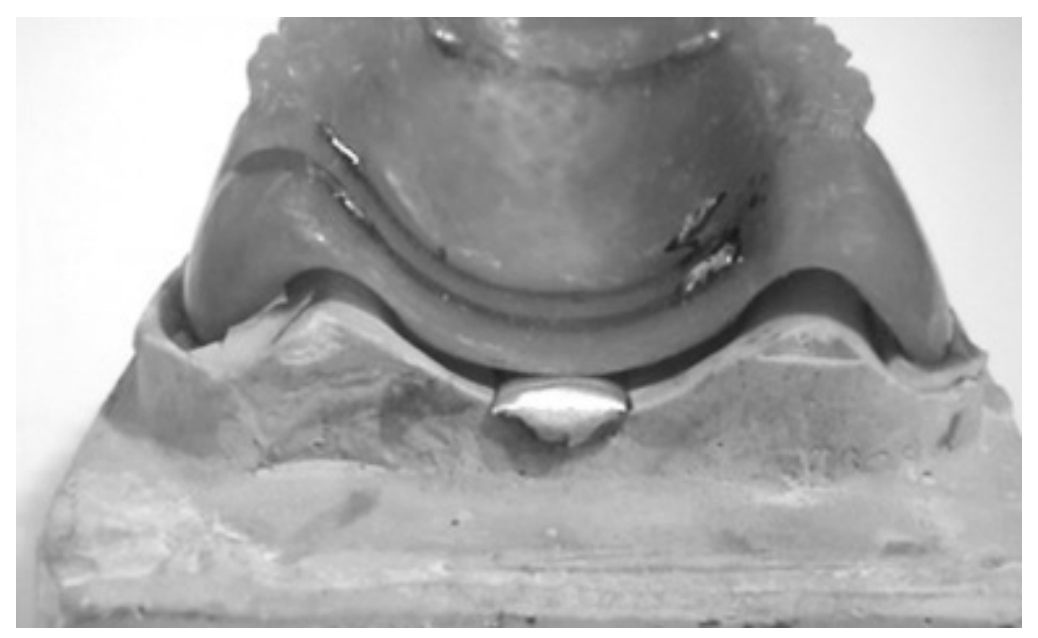

Figure 4. The loading cast of the upper edentulous jaw with a denture-specimen placed on it. The contact of the specimen along the metal midline of the palatal region can be seen. The two posterior silicone stoppers and the gap between the denture and the cast can be distinguished.

The self-curing resin (Paladur, Kulzer, Hanau, GERMANY) was poured into the silicone duplicating impression of the lower complete denture. After polymerization of the acrylic resin, the solid model of the entirely acrylic denture was removed from the impression.

A cast of the upper edentulous jaw with the wax model of the CUD and the model of the entirely acrylic cast of the lower complete denture was mounted in centric occlusion on an articulator. After the removal of the acrylic teeth on the solid acrylic model, the metal posterior teeth of the lower jaw (casting models) were placed in their anatomical position, using self-polymerizing resin, and in centric occlusion (Figure 5).

With the procedure above, a hybrid acrylic lower jaw cast was constructed, with metal posterior teeth. Also, when this mandibular hybrid cast is placed in a central occlusion with the identical dentures-specimens being on the hybrid cast of the upper jaw, the absolute parallelism of the bases of these two casts is ensured. In this way, when performing the fatigue experiment, it is ensured that the loads applied to the identical specimens-dentures are perpendicular to the masticatory level and parallel to the elongated axes of the artificial teeth.

\subsection{The Operation of the Fatigue Machine and the Cooperation of the Various Systems}

With the start of the fatigue machine and with the help of the time relay, which is appropriately synchronized, the production of the electric pulse with a frequency of $1 \mathrm{~Hz}$ (i.e., one pulse per second, begins) was initiated. Initially, with the help of the first load cell-dynamometer (that on the vertical base of the machine), an adjustment of the exerted load was made. If it is desired to reduce or increase the load, with the help of the pressure regulator, the pressure is reduced or increased until the dynamometer shows the desired load in kgrs (Figure 6).

The loading device exerts cyclic loads onto the complete denture specimens. The device was designed to generate a force of $80 \mathrm{kgrs}$ on the specimens. The load cycle was delivered at a rate of 1 cycle per second. The stress cycle is not a reversed cycle, so the force applied was only in one direction (Figure 7).

A graph of the data collected from the second dynamometer (load cell on the grip of the machine) was made. The load remains constant until the denture-specimen failed catastrophically (Figure 8).

Each current pulse passes through the electronic pulse meters and at the same time through the electromagnetic switches, and ends up in the electromagnetic air valve. The air piston begins to pull at the same frequency, while the pulse meters record the pulses. 


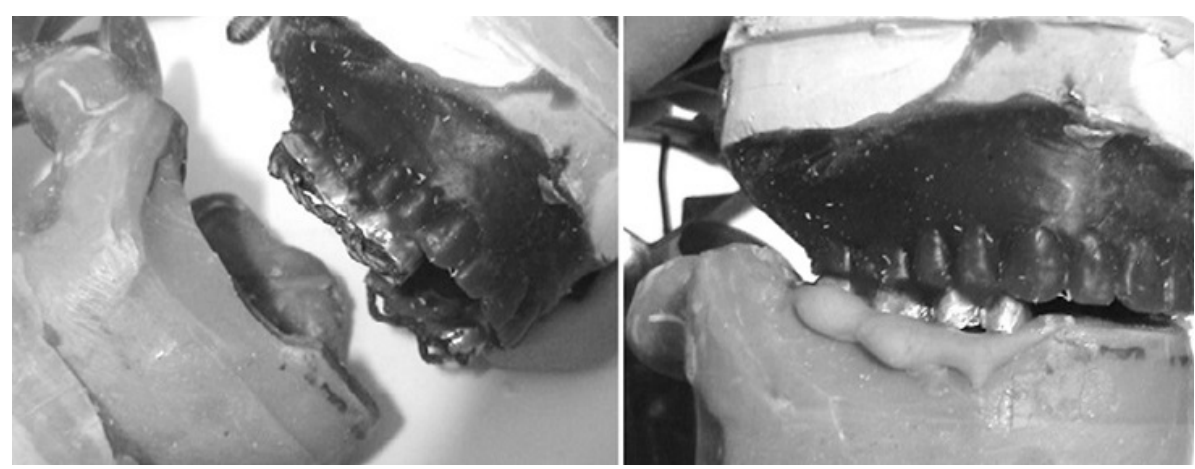

Figure 5. The metal posterior teeth of the lower jaw mounted in centric occlusion on the masticatory surfaces of the posterior teeth of the upper complete denture (left). Incorporation of metal teeth into the acrylic cast of the lower jaw using self-curing resin (right).

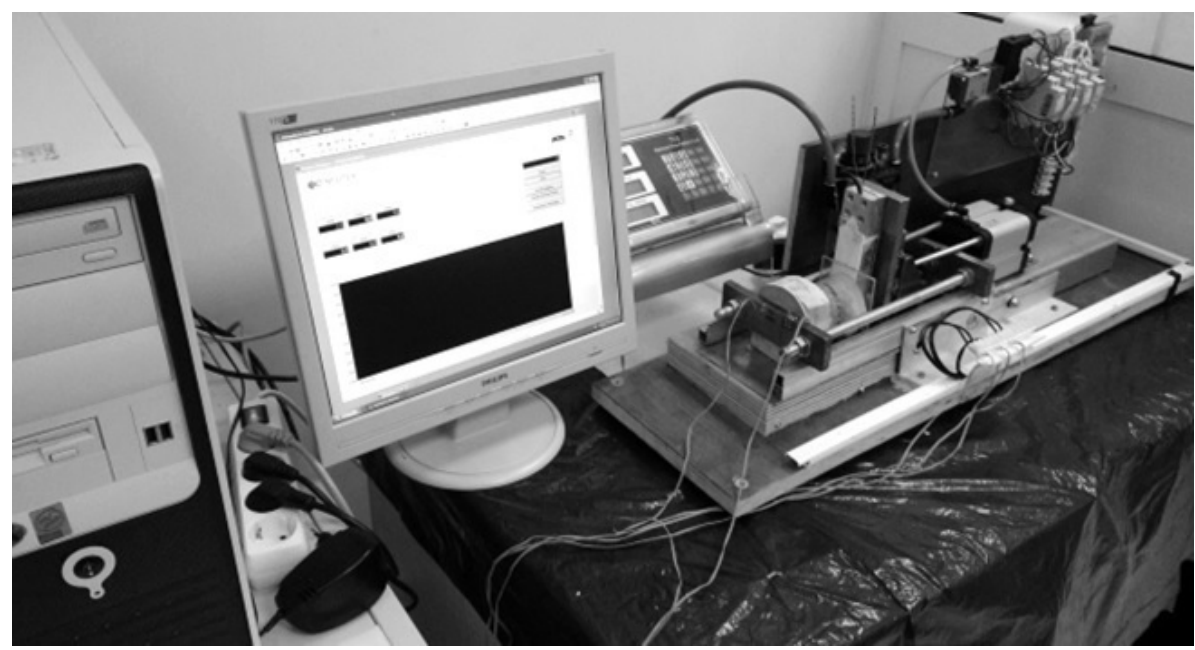

Figure 6. The assembled fatigue machine during the experiment.

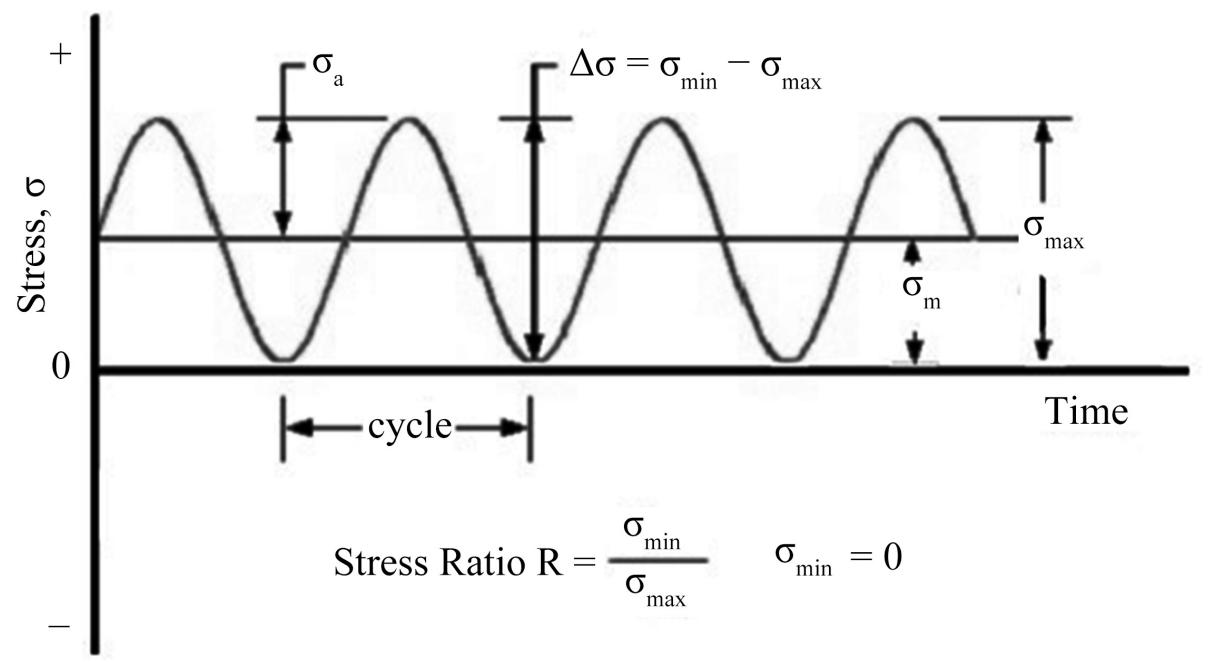

Figure 7. The graph depicts the cyclic loading that was applied (Redesign from Azzez [24]). 


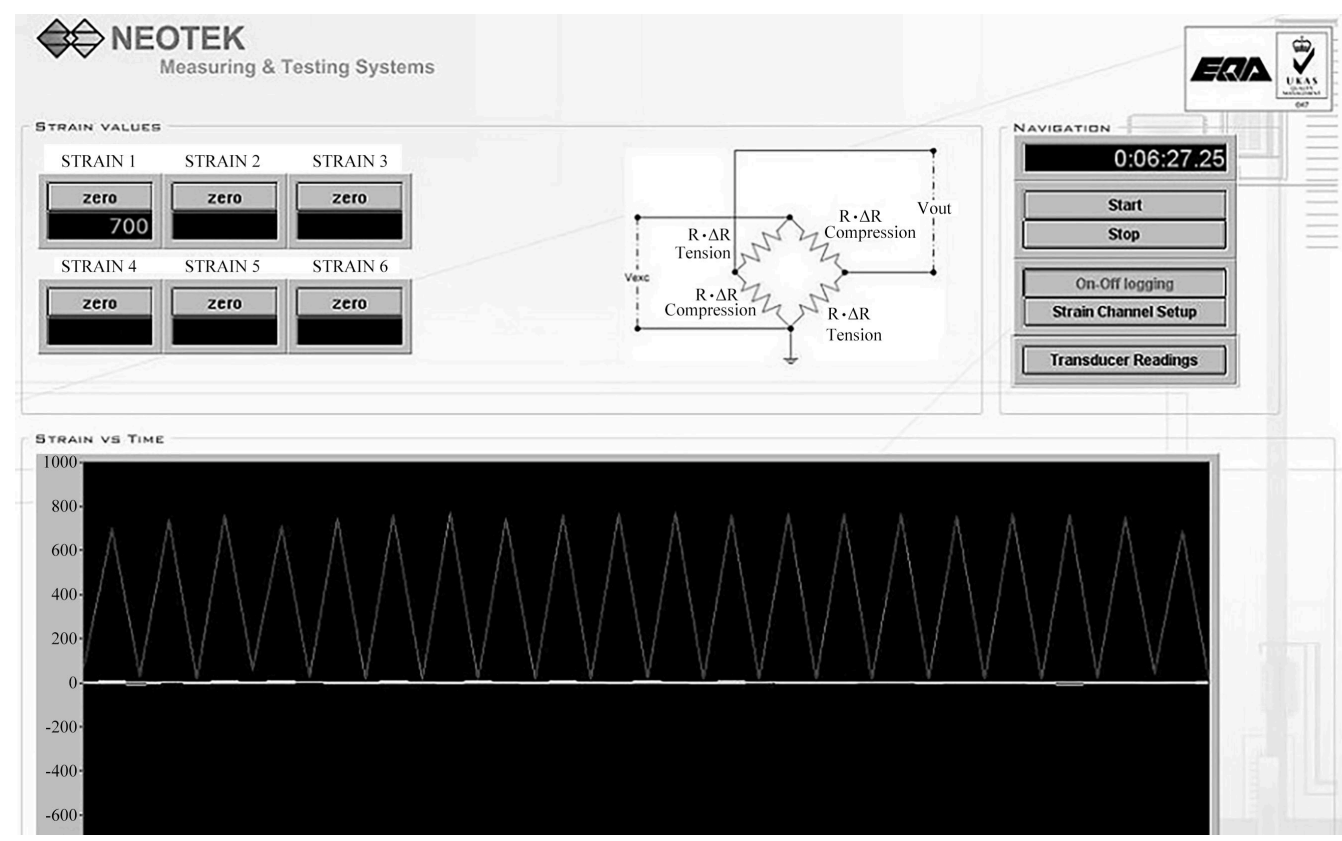

Figure 8. A graph of the data collected from the second load cell (the grip of the machine).

When a crack appears (according to the literature it is expected in the anterior palatal area) the operation of the corresponding pulse meter stops (due to crack, sensor opening and shutdown of the pulse meter) but the operation of the machine does not stop. When the crack propagates to the posterior palatal area, the operation of the second (rear) pulse meter is interrupted, with the same mechanism described for the anterior sensor. With the propagation of the crack along the entire length of the midline, the operation of the third electromagnetic switch is interrupted at which point the operation of the machine ceases. In this way, it is possible to detect the starting point of the crack, since at the end of the experiment if the two pulse meters have different indications, this means that the crack appeared at one point and extended to the other.

\section{MATERIALS AND METHOD}

The machine was designed, assembled and tested over the past five years in the laboratory of the Removable Prosthodontics of the Dental Technology Division of the Department of the Biomedical Sciences of the University of West Attica, in collaboration with the laboratories of the Microdent Co (Microdent, Dental Equipment and Service, Athens, Greece).

To test and evaluate the machine, a pilot study was conducted on the effect of reinforcing the strength of the complete upper denture (CUD) in fatigue. For this purpose, a total of 12 identical, complete denture-specimens were manufactured using the methodology described in detail in other research papers [25-28].

The denture-specimens were prepared using heat-polymerised acrylic resin (Paladon 65, Heraeus Kulzer, Hanau, Germany). Six of these dentures were without reinforcement, while the other six were reinforced in the anterior palate, incorporating a layer of six fibreglass meshes (Durostick, glass tape, DS-230 barges) per denture. The six meshes were integrated into each of the dentures during pressing of the acrylic resin in the flasks, using a sandwich technique applied in previous experimental work [29].

To perform the experiment, the fatigue machine was configured to carry a maximum load of $80 \mathrm{~kg}$ with a frequency of $1 \mathrm{~Hz}$, i.e., one current pulse or loadings per second. This frequency was thought to be close to the chewing frequency of the human oral system, which was found to be $1.53 \pm 0.22$ chews per second [30]. The load was greater than that which an edentulous patient could reasonably be expected to induce, in order to shorten the fracture time of each denture-specimen. No higher loading frequency was 
applied (to shorten the experiment) because increasing the frequency has been shown to cause an increase in the fatigue resistance of poly (methyl methacrylate) (PMMA) [31, 32]. If a loading force of around 12 $15 \mathrm{~kg}$ (according to the literature, the mean force exerted by edentulous patients) had been used, along with a frequency of $1 \mathrm{~Hz}$, then it would have required 4 - 5 years to break each complete denture-specimen $[23,30]$.

Figure 9 shows the entire acrylic fractured denture-specimen, with a copper sensor cemented to the outer surface, mounted on the hybrid cast of the upper jaw (Figure 9).

\section{RESULTS}

Table 1 shows the results of the loading cycles of the six identical denture-specimens in both the unreinforced and the reinforced state (Table 1).

As shown by the data in Table 1 , in the unreinforced specimens, the crack first appeared in the anterior palatal area (incisive papilla) in 33,537 loading cycles on average. After a number of loading cycles (approximately 33,775 cycles on average), the crack propagated to the posterior palate and caused the complete rupture (catastrophic failure) of the denture-specimen.

In the reinforced specimens of the present research, the crack appeared in the anterior palatal area after, on average, 149,191 loading cycles. In four of these specimens, the crack extended to the posterior palate area after an average of 48,014 loading cycles, causing the test pieces to fracture catastrophically. In the other two reinforced specimens, the crack did not extend to the posterior surface, so after an average of 462,546 loading cycles, the experiment was stopped. This phenomenon of preventing the propagation of cracks should be studied and analysed in future research.

Given that two groups of six specimens were examined, the Mann-Whitney non-parametric test was applied in order to compare two mean values from independent measurements. The average values used to perform the statistical evaluation of the data were the number of loading cycles completed before complete breakdown (catastrophic failure) of the denture-specimens and the shutdown of the machine. The difference between the mean values of the loading cycles of the two test groups was found to be statistically very significant, at a level much lower than $0.05(P=0.004)$.

Table 2 shows the results of the Weibull statistical analysis (Excel, Office Microsoft, USA), while Figure 10 shows the corresponding survival curves (Table 2, Figure 10).

According to previous research, the fracture of the CUD, with an average chewing load of $8-12 \mathrm{~kg}$, occurs after 2,000,000 loading cycles. Considering that the average number of loading cycles in one year is $400,000-500,000$, then the lifespan of a CUD is $4-5$ years [23].

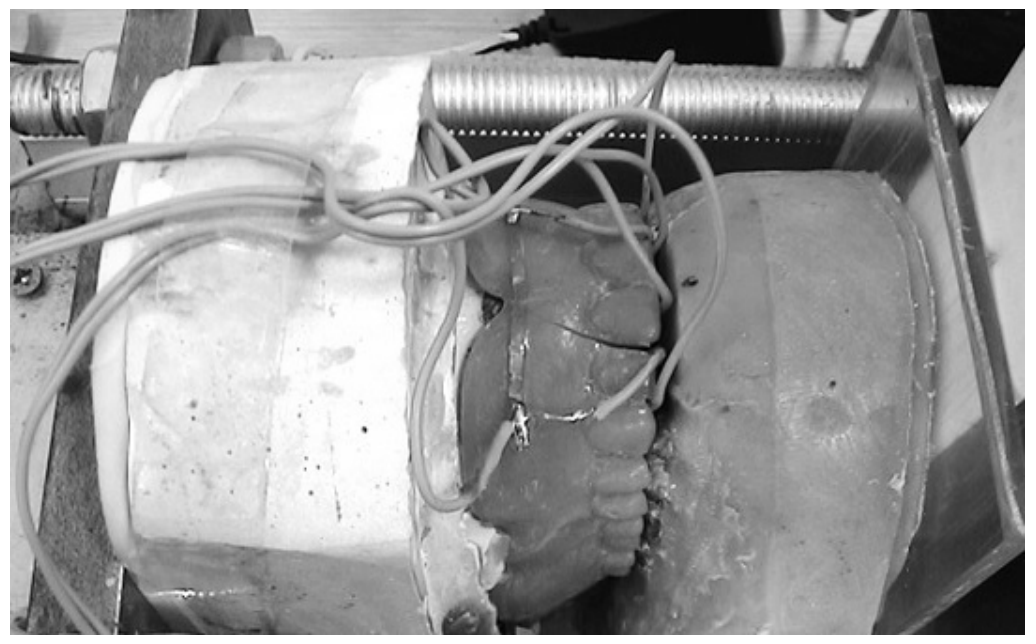

Figure 9. Complete rupture of the denture specimen and shutdown of the machine. 
The Weibull's survival chart of Figure 10, show that $80 \%$ of reinforced bases survived at least 150,000 loading cycles, while $80 \%$ of unreinforced bases survived at least 60,000 loading cycles. At lower survival rates, there was a strong deviation between the two Weibull survival curves, and $50 \%$ of reinforced bases survived at least 277,952 loading cycles, compared to 67,953 loading cycles for unreinforced bases.

From the average values of fatigue resistance (loading cycles) between the two groups, it appears that the reinforced bases had 4.2 times greater strength at a statistically very significant level $(284,630 / 67,312=$ 4.2; $P=0.004)$. Considering that the average lifespan of an unreinforced denture is 4.5 years [23], fibre-reinforced complete dentures can survive 19 years $(4.2 \times 4.5)$.

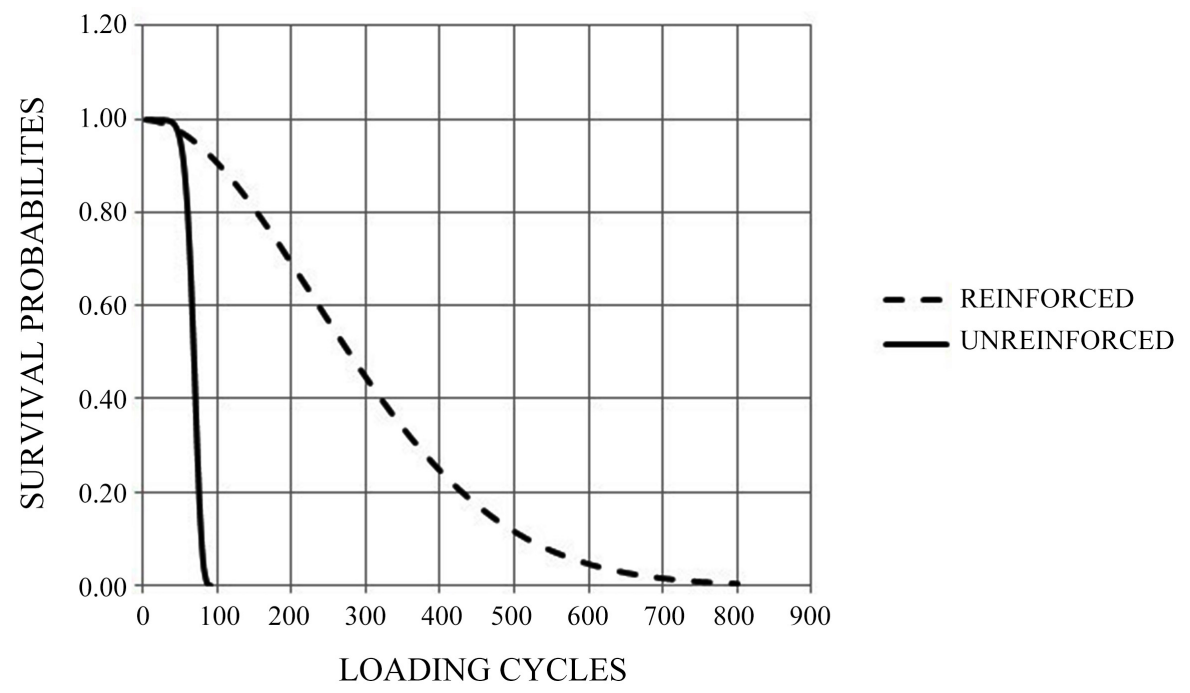

Figure 10. Survival chart according to Weibull analysis for reinforced and unreinforced dentures-specimens.

Table 1. Loading cycles until the catastrophic break of the dentures-specimens.

\begin{tabular}{|c|c|c|c|c|}
\hline \multirow[b]{2}{*}{ SPECIMEN } & \multicolumn{2}{|c|}{ Unreinforced } & \multicolumn{2}{|c|}{ Reinforced } \\
\hline & APS & PPS & APS & PPS \\
\hline 1 & 28,631 & 56,942 & 139,481 & 187,218 \\
\hline 2 & 39,328 & 77,455 & 139,196 & 186,861 \\
\hline 3 & 34,933 & 72,853 & 157,658 & $538,324^{*}$ \\
\hline 4 & 29,952 & 61,675 & 160,591 & 208,937 \\
\hline 5 & 36,765 & 71,551 & 151,367 & 199,676 \\
\hline \multirow[t]{2}{*}{6} & 31,613 & 63,399 & 146,856 & $386,769^{*}$ \\
\hline & $\begin{array}{c}\mathrm{MV}=33,537 \\
\mathrm{SD}=4159\end{array}$ & $\begin{array}{c}\mathrm{MV}=67,312^{\star *} \\
\mathrm{SD}=7825 \\
\mathrm{CV}=11.62\end{array}$ & $\begin{array}{c}\mathrm{MV}=149,191 \\
\mathrm{SD}=9011\end{array}$ & $\begin{array}{c}M V=284,630^{* *} \\
S D=146,142 \\
C V=51.34\end{array}$ \\
\hline
\end{tabular}

APS: Anterior Palatal Sensor (counter 1), PPS: Posterior Palatal Sensor (counter 2), MV: Mean Value, SD: Standard Deviation, CV: Coefficient of Variation, ${ }^{\star}$ The experiment was stopped, ${ }^{\star \star}$ The two means are different at a very significant level $(P=0.004)$. 
Table 2. Weibull analysis results for denture-specimens with and without reinforcement.

\begin{tabular}{ccc}
\hline & RS & US \\
\hline $\begin{array}{c}\beta \text { or Shape parameter } \\
\alpha \text { or Characteristic life } \\
\text { ANOVA }\end{array}$ & 8.32 & 1.46 \\
Significance $F$ & 35,390 & 302,465 \\
RELIABILITY & 0.0007 & 0.044 \\
$0.01 \%$ & & \\
$0.1 \%$ & 741,924 & \\
$0.5 \%$ & 517,951 & 84,196 \\
$0.9 \%$ & 277,952 & 77,843 \\
$1 \%$ & 104,663 & 67,953 \\
\hline
\end{tabular}

RS: Reinforced Specimens, US: Unreinforced Specimens.

The distribution of the survival curve of the reinforced bases shows a weak scatter of values when compared to the distribution of the unreinforced bases. This is confirmed by the large standard deviation (Table 1) of the reinforced base group and is a common finding in fibre-reinforced specimens where fatigue resistance is related to the location of the fibres and the degree of fibre integration in the acrylic matrix. Various mechanisms have been suggested to be responsible for the fatigue fracture of fibre-reinforced dental acrylic resins [32]. This explains the weak scatter of the fatigue test data and is also confirmed by the high variation of the means in the group $(\mathrm{CV}=51.34)$.

\section{DISCUSSION}

In some studies, using machines of own design and construction, the samples of the acrylic denture bases were kept with the non-tissue side, that is the acrylic teeth, on the platform of the testing machine and a round plunger was placed in midline on the most prominent point of the tissue surface of the palate, between premolar and molar region, for loading in compression. In addition, shorter experiments applied a frequency of $3.3 \mathrm{~Hz}$ (i.e., approximately three loadings per second) [20-22]. This frequency is much higher than the frequency of masticatory loads in the oral cavity, which is $1.5 \mathrm{~Hz}$ (i.e., one and a half loadings per second). The frequency of $1 \mathrm{~Hz}$, which is close to $1.5 \mathrm{~Hz}$, was chosen to conduct the experiments of the present study in combination with the deployment of a high load $(80 \mathrm{~kg})$ in cyclic loading [30]. The use of the higher load favours the strong scatter of data, in contrast to the use of the higher frequency, which weakens the scatter of the data. Furthermore, a high load does not replicate the partial relaxation of the stresses during mastication, where the load is exerted with lower frequency [13, 23, 31, 32].

The machine in this study was designed in such a way that the grip of the machine compressed the lower denture over the upper one in central occlusion, in the same way that the two masticatory muscles pull the lower jaw over the upper jaw during chewing.

Another important innovation of this machine, compared to previous ones, is the ability to detect the moment of the appearance of the crack and how it propagates, using special switches and sensors mounted on the surface of the denture-specimen, interconnected with a special circuit. With this method, it was found that in all tests of identical dentures, the crack initially appeared in the anterior palatal area (the area of the incisive papilla) and, after a number of loading cycles, it propagated backwards and led to the com- 
plete separation of the denture into two pieces. The results of this study confirm previous research into the deformation of the CUD that showed that during loading, the maximum tensile stress tends to develop in the anterior palatal region, approximately in the area of the incisive papilla $[23,25,27]$. It has also been demonstrated that the area of the notch for the labial frenum is not the starting point of the crack, since this specific stress field is characterised by two compressive principal stresses. These stresses are more beneficial than detrimental in the process of starting a crack in this area [28]. For all these reasons, it seems that reinforcing the anterior residual ridge and the anterior palate area of the denture, as applied in this study, is sufficient and significantly improves its resistance to fatigue.

Experimental research has shown that during the application of masticatory loads, the CUD bends on the midline of the palate, which acts as a lever, while at the same time, it undergoes torsion around the midline axis that coincides with the medial sagittal axis [1]. Based on this assumption, the study of resins for the manufacture of complete dentures and the mechanical deformation of their bases should not be carried out under conditions of purely flexural deformation, but rather under conditions of simultaneous bending and torsion. The only test that ensures the aforementioned loading conditions is the fatigue test of the CUD in simulated conditions of the experiment with the loading conditions of the denture in the oral cavity during its operation.

The statistically significant difference between the strength of the unreinforced and reinforced denture-specimens proves, on one hand, the effectiveness of the sandwich technique for incorporating fibreglass mesh into the specimens and, on the other hand, the reliability of the fatigue machine. The low coefficient of variation of the unreinforced denture-specimen group $(\mathrm{CV}=11.62)$, considered more internally homogeneous compared to the reinforced specimens, shows the repeatability of the results and the reliability of the fatigue machine.

The factors to be considered in the practical application of this machine are on the one hand the fact that the fatigue is dry (without the presence of artificial saliva) and on the other hand that the machine will not stop operating until the generated crack propagates to the most posterior or anterior area of the denture leading to complete fracture. The dry conditions of the experiment are not a problem in comparative studies as all the specimens are loaded under the same conditions. As for the automatic cessation of the machine, this is not possible if the crack formed does not extend along the entire length of the specimen. In these cases, the experiment is interrupted.

Moreover, the view has been expressed in the past that in fatigue experiments on PMMA there is a problem of deciding when fatigue failure occurs and that some plastics continue to undergo cyclic deformation for a long time after the initial crack deformation. It appears from amongst all this confusion that the most important point is to define failure [19].

\section{CONCLUSIONS}

1) The fatigue machine presented in this study provides a reliable way of straining the CUD in complete simulation of the oral conditions of mastication, by submitting the complete denture-specimens to a combination of flexural and torsional loading.

2) The incorporation of glass fibres in the CUD by means of a sandwich technique quadruples the lifespan of the denture.

3) The fracture model of the unreinforced CUD includes the appearance of the fracture crack in the anterior palate area and its propagation to the posterior palate, causing the complete rupture of the denture.

4) The reinforcement of the anterior palatal region with an extension on the anterior residual ridge, without the extension of the fibres in the posterior region, is sufficient to strengthen the denture.

5) The low standard deviation, but also the low coefficient of variation (CV), of the group of unreinforced dentures shows the repeatability of the results and the reliability of the machine.

6) The high standard deviation and coefficient of variation of the reinforced dentures was expected, since a high variation of results is usually recorded in fibre reinforcement cases. 


\section{ACKNOWLEDGEMENTS}

We would like to thank Kulzer Company and its representative in Greece, Mrs. Mary Konstantinidou, for their significant support and assistance in carrying out this study. We also thank Mr. Tasos Stamatonikolos and his company MICRODENT for technical support and advice when assembling the machine.

\section{CONFLICTS OF INTEREST}

The authors declare no conflicts of interest regarding the publication of this paper.

\section{REFERENCES}

1. Prombonas, A.E., Paralika, M.A. and Poulis, N.A. (2013) Investigation of the Torsional Deformation of the Complete Upper Denture: A Pilot Study. Journal of Biomedical Science and Engineering, 6, 443-448.

https://doi.org/10.4236/jbise.2013.64055

2. Strzelecki, P., Sempruch, J. and Nowicki, K. (2015) Comparing Guidelines Concerning Construction of the S-N Curve within Limited Fatigue Life Range. Polish Maritime Research, 22, 67-74.

https://doi.org/10.1515/pomr-2015-0058

3. Rajesh, S. and Saravanan, N. (2016) Design and Fabrication of Low-Cost Fatigue Test Rig. Imperial Journal of Interdisciplinary Research, 2, 684-688.

4. Alaneme, K.K. (2011) Design of a Cantilever-Type Rotating Bending Fatigue Testing Machine. Journal of Minerals and Materials Characterization and Engineering, 10, 1027-1039. https://doi.org/10.4236/jmmce.2011.1011078

5. McAlorum, J., Rubert, T., Fusiek, G., Niewczas, P. and Zorzi, G. (2018) Design and Demonstration of a LowCost Small-Scale Fatigue Testing Machine for Multi-Purpose Testing of Materials, Sensors and Structures. Machines, 6, 30-43. https://doi.org/10.3390/machines6030030

6. Shashidhar, M.B., Ravishankar, K.S. and Padmayya, S.N. (2018) A Review on Design and Fabrication of Fatigue Testing Machine. International Journal of Novel Research and Development, 3, 5-14.

7. Bustos, F.M.P. and Vargas, C.A.Á. (2012) Design and Construction of a Torsional Fatigue Testing Machine Operated by Inertial Loads. Dyna, 172, 46-55.

8. Santosh, J.C., Aarti, M., Akanksha, J., Rahul, J., Abhir, B. and Rohit, J. (2016) Design and Fabrication of Rotating Bending Fatigue Testing Machine-A Laboratory Development Project. International Research Journal of Engineering and Technology, 3, 816-819.

9. Deacon, J.A. and Monismith, C.L. (1967) Laboratory Flexural-Fatigue Testing of Asphalt-Concrete with Emphasis on Compound-Loading Tests. 45th Annual Meeting of the Committee on Mechanical Properties of Bituminous Mixtures, 1-31. http://onlinepubs.trb.org/Onlinepubs/hrr/1967/158/158-001.pdf

10. Di Franco, G., Marannano, G., Pasta, A. and Mariotti, G.V. (2011) Design and Use of a Fatigue Test Machine in Plane Bending for Composite Specimens and Bonded Joints. In: Attaf, B., Ed., Advances in Composite Materials - Ecodesign and Analysis, IntechOpen, London, 491-516. https://doi.org/10.5772/14480

http://www.intechopen.com/books/advances-in-composite-materials-ecodesign-and-analysis/design-and-useofa-fatigue-test-machine-in-plane-bending-for-composite-specimens-and-bonded-joints

11. Gentile, D. (2012) Design and Realization of a Multisamples Rotating High Cycle Fatigue Machine. Frattura ed Integrità Strutturale, 22, 85-92. https://doi.org/10.3221/IGF-ESIS.22.09

12. Jordaan, J.P. (2018) Four-Point Bending Fatigue Test Specimen Design by FEA. $R$ and $D$ Journal of the South African Institution of Mechanical Engineering, 34, 1-8. http://www.saimeche.org.za

13. Oliveira, C.J., Da Silva, G.D.C., Priscila, H., Santos, G.M. and Sousa, L.A. (2017) Design and Construction of a 
Machine for Fatigue Tests by Rotation and Flexion. Proceedings of the 7 th International Conference on Mechanics and Materials in Design, Albufeira, 11-15 June 2017, 769-778.

14. Şik, A., Atak, A., Yavuz, C. and Özdemir, V. (2018) The Design of Fatigue Strength Machine Being One of the Methods for Determining the Mechanical Properties of the Materials Used in the Industry. Gazi University Journal of Science, 5, 79-88.

15. Surati, C. and Hira, P. (2016) Design and Development of Fatigue Testing Machine. International Journal of Engineering Research and Generic Science, 4, 572-579.

16. Balcioğlu, E., Sakin, R. and Gün, H. (2018) Development of Fixed End Type Flexural Fatigue Test Machine and Static and Dynamic Behaviour of Glass/Epoxy Laminated Composite. IV International EGE Composite Materials Symposium, Izmir, 6-8 September 2018, 300-317. https://doi.org/10.17515/resm2018.67me0917

17. Sanchez, E.C.M., Meggiolaro, M.A. and De Castro, J.T.P. (2015) Development of an Axial-Torsion Biaxial Fatigue Testing Machine. 23rd ABCM International Congress of Mechanical Engineering, Rio de Janeiro, 6-11 December 2015, 23-32.

https://www.researchgate.net/publication/315550627 Development of an axial - torsion biaxial fatigue testi ng_machine

18. Banavasi, S.M., Ravishankar, K.S. and Padmayya, S.N. (2018) A Review on Design and Fabrication of Fatigue Testing Machine. International Journal of Novel Research and Development, 3, 5-14.

19. Stafford, G.D., Lewis, T.T. and Huggett, R. (1982) Fatigue Testing of Denture Base Polymers. Journal of Oral Rehabilitation, 9, 139-154. https://doi.org/10.1111/j.1365-2842.1982.tb00544.x

20. Vallittu, P.K., Lassila, V.P. and Lappalainen, R. (1996) The Effect of Notch Shape and Self-Cured Acrylic Resin Repair on the Fatigue Resistance of an Acrylic Resin Denture Base. Journal of Oral Rehabilitation, 23, 108-113. https://doi.org/10.1111/j.1365-2842.1996.tb01218.x

21. Vallittu, P.K. (1996) Comparison of the in Vitro Fatigue Resistance of an Acrylic Resin Removable Partial Denture Reinforced with Continuous Glass Fibres or Metal Wires. Journal of Prosthodontics, 5, 115-121.

https://doi.org/10.1111/j.1532-849X.1996.tb00285.x

22. Vallitu, P.K., Lassila, V.R. and Lappalainen, R. (1994) In Vitro Fatigue Fracture of an Acrylic Resin Based Partial Denture-An Exploratory Study. Journal of Prosthetic Dentistry, 72, 289-295.

https://doi.org/10.1016/0022-3913(94)90342-5

23. Vlissidis, D. and Paipetis, S.A. (1984) The Mechanical Strength of Maxillary Complete Dentures. Journal of Biomedical Materials Research, 18, 413-425. https://doi.org/10.1002/jbm.820180409

24. Azeez, A.A. (2013) Fatigue Failure and Testing Methods. Bachelor's Thesis, HAMK University of Applied Sciences, Hämeenlinna.

25. Prombonas, A. and Vlissidis, D. (2002) Effects of the Position of Artificial Teeth and Load Levels on the Stress in the Complete Maxillary Denture. Journal of Prosthetic Dentistry, 88, 415-422.

https://doi.org/10.1067/mpr.2002.128174

26. Prombonas, A. and Vlissidis, D. (2006) Comparison of the Midline Stress Fields in Maxillary and Mandibular Complete Dentures: A Pilot Study. Journal of Prosthetic Dentistry, 95, 63-70.

https://doi.org/10.1016/j.prosdent.2005.11.009

27. Prombonas, A. and Vlissidis, D. (2009) Analysis of Stresses in Complete Upper Dentures with Flat Teeth at Differing Inclinations. Medical Engineering and Physics, 31, 314-319.

https://doi.org/10.1016/j.medengphy.2008.06.008

28. Prombonas, A.E., Vlissidis, D.S., Paralika, M.A. and Poulis, N.A. (2012) The Stress State of the Fraenal Notch Region in Complete Upper Dentures. Medical Engineering and Physics, 34, 1477-1482. 
https://doi.org/10.1016/j.medengphy.2012.02.009

29. Mallikarjuna, M.H.B., Shaik, S., Sachdeva, H., Khare, S., Haralur, S.B. and Roopa, K.T. (2015) Effect of Reinforcement Using Stainless Steel Mesh, Glass Fibres, and Polyethylene on the Impact Strength of Heat Cure Denture Base Resin-An in Vitro Study. Journal of International Oral Health, 7, 71-79.

30. Farooq, M. and Sazonov, E. (2016) Automatic Measurement of Chew Count and Chewing Rate during Food Intake. Electronics, 5, 62-76. https://doi.org/10.3390/electronics5040062

31. Smith, D.C. (1962) Recent Developments and Prospects in Dental Polymers. Journal of Prosthetic Dentistry, 12, 1066-1078. https://doi.org/10.1016/0022-3913(62)90162-2

32. Baran, G., Boberick, K. and McCool, J. (2001) Fatigue of Restorative Materials. Critical Reviews in Oral Biology and Medicine, 12, 350-360. https://doi.org/10.1177/10454411010120040501 